\title{
SEXUAL HARASSMENT AND ITS EFFECTS ON THE MENTAL HEALTH OF THE ADOLESCENTS SCHOOL GIRLS IN LALITPUR AND RUPANDEHI DISTRICT
}

\author{
Kalpana Gyawali \\ Lecturer, Sanothimi Campus, Bhaktapur, TU. \\ Corresponding author: gpkalpana81@gmail.com
}

\begin{abstract}
A cross-sectional study was conducted to find the prevalence of mental health on adolescent girl students and the effect of sexual harassment on their mental health: depression, anxiety, and stress. A concurrent mixed method was used and the study was conducted at both community and institutional schools of Lalitpur and Rupendehi districts. A semi-structured questionnaire was used for quantitative data collection along with depression, anxiety and stress score test (DASS -42 points) to measure depression, anxiety, and stress. Focus group discussion (FGD), in-depth interviews (IDI), and key informant information (KII) were used for qualitative data collection. Poor and ill mental health were found among the respondents and the prevalence of depression, anxiety and stress were $45 \%, 52 \%$, and $35 \%$ respectively among the sexually harassed girls. As sexual harassment was found as one of the major factors that is responsible for the poor mental health status of girl students, it is necessary for every school to adopt antisexual harassment policies and to take action against it to create a healthy learning environment.
\end{abstract}

Keywords: depression - anxiety - stress - mild - moderate - severe.

\section{INTRODUCTION}

Different forms of sexual harassment and violence have been seen from ancient time as different names such as Devdasi, Apsara, Sati system, forced child marriage, and less freedom for women in different holy books of Hindu religions, the higher status of the male monk in Buddhism women as a way of sin in Christianity and Burka system in Muslim religions (Mohapatra 2015). Though the term sexual harassment 
became popular only after 1970 (Farley 1978). Various acts are considered sexual harassment and hard to find a single most definition. At the International level, the United Nations General Recommendation 19 to the Convention on the Elimination of all Forms of Discrimination Against Women defines sexual harassment including such unwelcome sexually determined behaviour as physical contact and advances, sexually coloured remarks, showing pornography and sexual demands, whether by words or actions. Such conduct can be humiliating and may constitute a health and safety problem; it is discriminatory when the woman has reasonable ground to believe that her objection would disadvantage her in connection with her employment, including recruitment or promotion, or when it creates a hostile working environment (UN women 2009). Further United States Merit System Protection Board (USMSB 1985) has categorized sexual harassment into three groups according to their severity which are; less severe (unwelcome sexual verbal remarks, suggestive looks and gestures, and deliberate touching); moderately severe (pressure for dates, pressure for sexual favours, unwelcome letters, and telephone calls); and most severe types of sexual harassment (actual or attempted rape or sexual assault and abuse).

Sexual harassment is not only a physical crime against girls and women but has been found responsible for their poor physical and emotional health. Lee et al. (1996) have reported that sexual harassment can have negative academic, psychological, and behavioural impacts on the victim. Several studies (Bagley et al. 1997, Jones et al. 2008, \& MSI 2008. Rowe 1996) also illustrated the consequences of sexual harassment on students such as children's health and safety, enrolment, and educational achievement and dignity, and social relationships in the victim of sexual harassment. According to AAUW (2001), nearly half of all the students who experienced sexual harassment felt very or somewhat upset right after the harassment. Sexual harassment also has been reported as a detrimental factor in productivity and performance as well as the psychometric health of the students (Berman et al. 2000, Dahinten 1999). Hill and Kearl (2011) reported similar effects in an American school where 22\% of girls felt trouble sleeping and $37 \%$ of girls did not go to school. Similarly, Anderson (2011) has reported that nearly half of the girls of the grade 7 to 12 experienced sexual harassment in the USA and $87 \%$ of the girls who 
are harassed reported negative effects such as absenteeism, insomnia, and stomach-ache. Girls are suffering from sexual violence and harassment in schools also found with poor health status and as well as has poor education achievement (Anderson 2011, Hill \& Kearl 2011, Okeke 2011, Plan 2008). Similarly, according to, Crick and Bigbee, (1998) children who persistently are victimized by sexual harassment and violence suffer from higher levels of depression, anxiety, and loneliness in comparison to non-victimized children. The above-mentioned studies indicated that sexual harassment has been found as a causative factor of major social and mental health problems on victims. According to the World Health Organization (WHO 2004), mental health is a state of well-being in which the individual realizes his or her abilities, can cope with the normal stresses of life, can work productively and fruitfully, and can make a contribution to his or her.

In Nepalese context also, girl students are likely to be sexually harassed by different persons at different places (Gyawali et al. 2012, Mishra \& Lamichane 2018, Thapalia et al. 2020). Though many international studies excavated the negative effects of sexual harassment on mental health situations, in the Nepalese context it has not been studied well in relation to the present context. Hence, this study is intended to explore the effects of sexual harassment on mental health with mental health problems of adolescent girl students (teenage) and the result of this study would be useful for schools to create an ideal place for study to girl students by which they can achieve their objectives to be educated and healthy citizen.

\section{METHODOLOGY}

The research design used in the study was the concurrent mixedmethod (Creswell 2014). The sample size for quantitative data has been calculated at a $95 \%$ confidence level with a 5\% confidence interval and the sample size was 371 from Lalitpur and 402 from Rupandehi district. Adolescent girl students of both public and institutional schools from two districts (Lalitpur and Rupandehi) were selected for the study. For qualitative data collection, focus group discussion (FGD), key informants' interviews (KII), and in-depth interviews (IDI) were conducted. IBM SPSS 20 software was used for quantitative data analysis and the test of independence among variables was carried out with the Chi-square test. 
For qualitative data, IDI, KII, and voices of FGDs have been transcribed. Findings of quantitative data have been triangulated with the findings of qualitative data wherever possible.

The situation of mental health effects (depression, anxiety, and stress) was measured with the help of the Depression, Anxiety, Stress Scale (DASS) (Lovibond \& Lovibond 1995). The DASS is a 42-item questionnaire that includes three self-report scales designed to measure the negative emotional states of depression, anxiety, and stress and found helpful in ruling out cases with an anxiety disorder or depression in a population with mental health problems (Nieuwenhuijsen et al. 2003). DASS has been found reliable and valid scales for assessing clients and has been tested its validity and reliability (Afzali et al. 2007, Basha \& Kaya 2016, Tran et al. 2013). The other perceived effects of mental health due to the sexual harassment of girl students were measured with structured questionnaires.

\section{RESULTS AND DISCUSSION}

\section{Situations of depression, stress, and anxiety level on sexually harassed girl students}

Different levels of mental illness (depression, stress, and anxiety) were observed on adolescent girl students due to sexual harassment. Among those three mental illnesses, $45 \%$ of students were suffering from some degree of depression (Table 1), and within the different depression levels, 31 percent were having mild to moderate levels of depression while $14 \%$ were severe to extremely severe levels. In contrary to sexually harassed girls, the prevalence of depression level was lower (16\%) in those girls who have not felt sexual harassment in comparison to sexually harassed ones (45\%). The extremely severe level of depression was only found among the girls who had been sexually harassed. Similarly, mild to extreme level of depression was found higher in institutional school and also at Lalitpur district visa-vies compared to community schools and Rupandehi district respectively. 


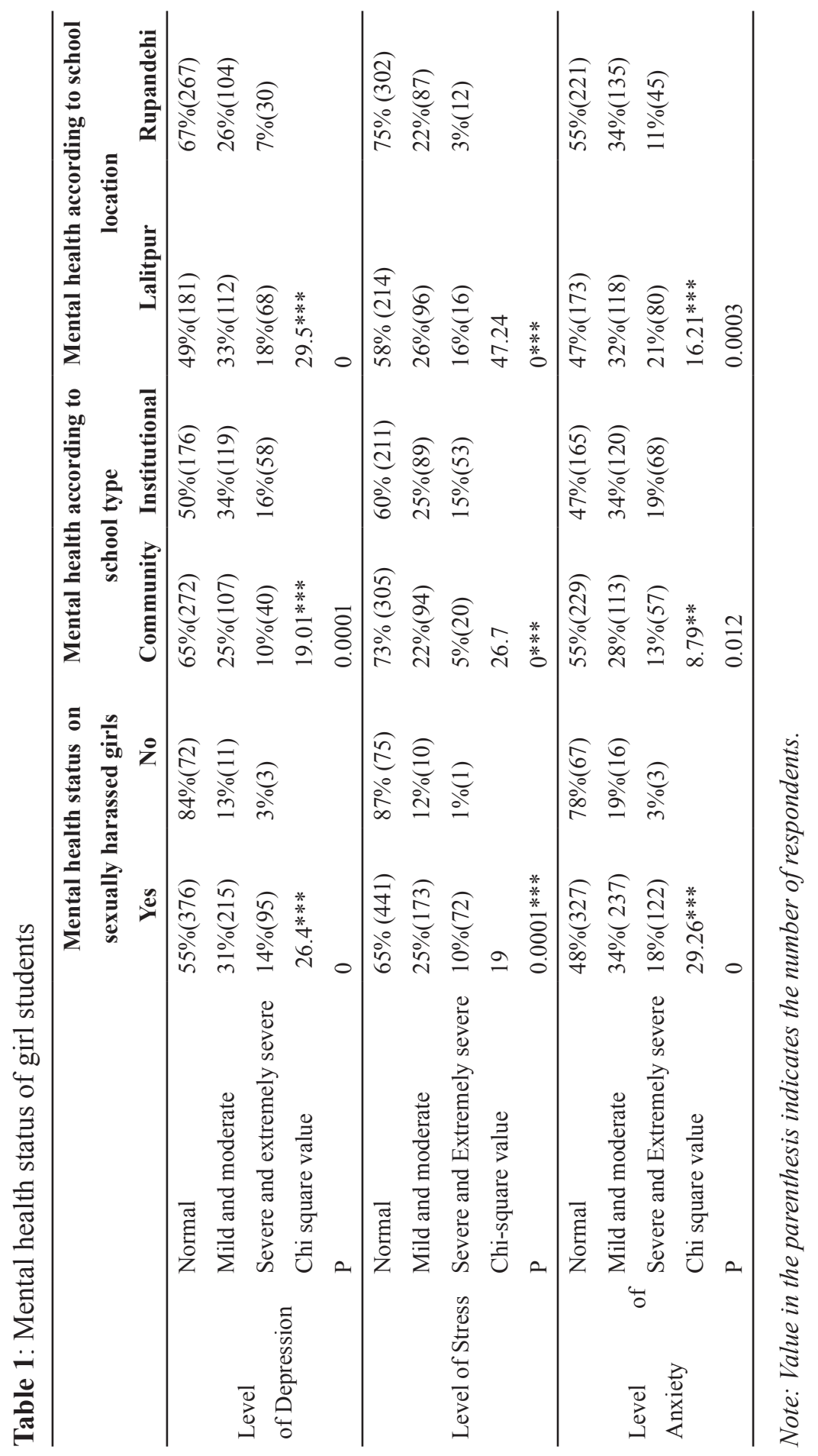


In the case of stress level, $35 \%$ of the respondents were suffering from a different level of stress and among them, $25 \%$ of the students were suffering from a mild to moderate level of stress while $10 \%$ of the students were suffering from a severe to the extreme level of stress, and $2 \%$ students were suffering from an extremely severe level of stress. It was observed that among the respondents who had not experienced sexual harassment the stress at a different level was lower that is only $13 \%$ of them had stress problems in comparison to $35 \%$ in the case of sexually harassed girl students (Table 1).

The situation of anxiety level was higher among sexually harassed girls. Among respondents, $52 \%$ of the students were at a different level of anxiety (mild to extremely severe) and it was found that $35 \%$ of them were at a mild to moderate level of anxiety and other hands $18 \%$ the respondents were found suffering from severe to extremely severe level of anxiety (Table 1).

The prevalence of different levels of depression, stress, and anxiety (mild to extremely severe) were found higher at Lalitpur district and in the girl students of the institutional school as compared to Rupandehi district and community school respectively. The difference in the prevalence of different level of depression, stress, and anxiety among the girl students were also statistically significant at $0.001 \%$ significant level (Table 1 ).

Among the three mental health parameters, anxiety was the most common type of mental problem in the girl students in comparison to depression and stress (Figure 1), and the girls with stress levels were lesser than anxiety and depression. The highest level of depression was seen in Lalitpur district. The stress was the highest among the

sexually harassed girls and the anxiety was the highest at Lalitpur district among the girls from institutional schools. The lowest level of depression, stress, and anxiety were found among the girl students who do not have suffered from sexual harassment (Figure 1).

According to the Focus Group Discussion, participants reported that they felt fear, depression, irritation, frustration, tension, humiliation, and sleeping disorder. Sexual harassment was the major cause of the mental health effects that were caused by teachers, friends (boys), relatives, and strangers. There are some remarks by the respondents which are as follows. 


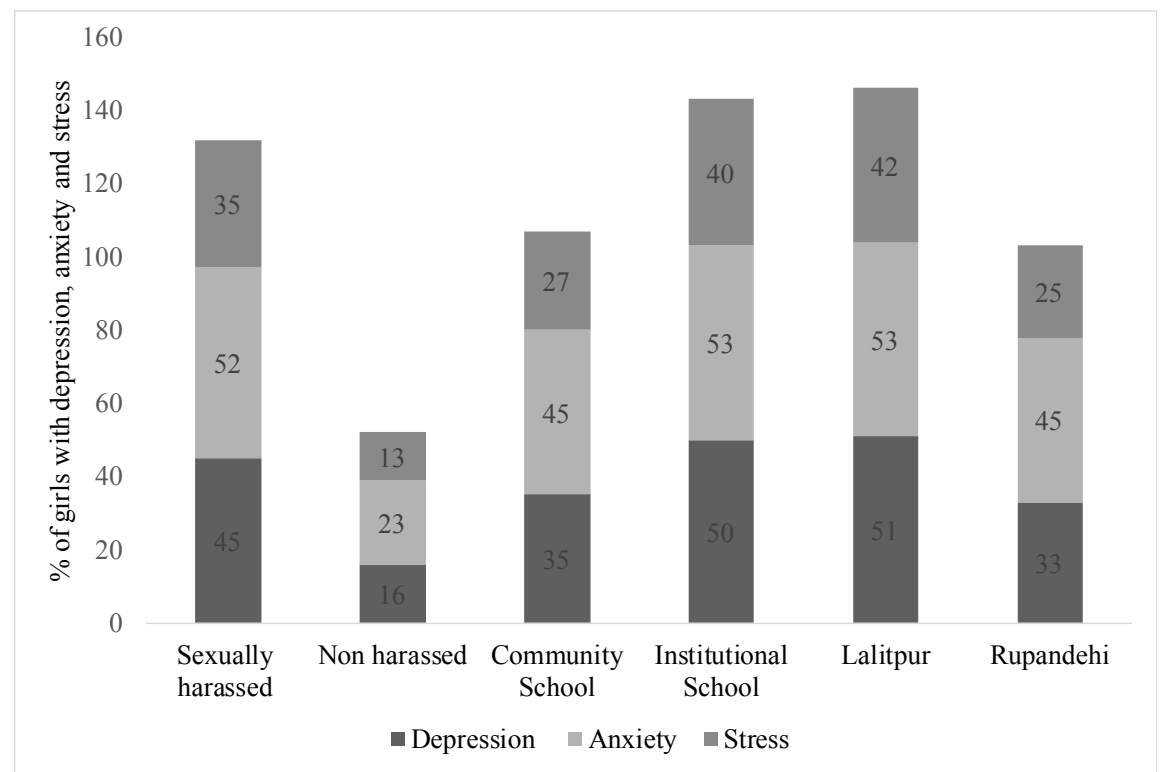

Figure 1: Percentage of girl students having depression, anxiety, and stress (mild to extremely severe level)

When I see that teacher, who always tries to do harass me my body starts shaking and my legs become imbalanced and weak. I feel fear hoping that he would not touch me again, brush with my body again, and in the future too (FGD 5, Lalitpur, Community, R.N.5, Dalit).

When the teacher started sexually harassing me, my legs were trembling, and started sweating from my body which made me weak and fearful for many days. When I still think about that event, I feel fear and my body starts freezing. If I remember that event at night, it is hard to sleep properly (IDI -G, Lalitpur, institutional, Janjati).

I feel tension and depression because of boys' harassing behaviours, sometimes when I think about their behaviours I became sad and want to cry and we have study stress as well (FGD 6, Lalitpur, Institutional, R.N. 3, Janajati).

I had shared my problem with my mom but she said that our uncle had done much helps for us so she requested me to be silent and safe. But I was depressed and fear of his sexual harassment (IDI -H, Lalitpur, Community, Janjati). 
I felt fear and depressed about my brother in law's (Bhinaju) sexual assaulting behaviour. In the beginning, it was hard to sleep properly because of that sexual assault (IDI-D, Rupandehi, Institutional, Dalit).

There was a teacher for lower secondary classes in our school. Once a group of girl students complained us about him and they said that he was doing sexual harassing behaviours with them. They were also looking frightened and nervous during that time. After that, we initiated the process to transfer him and now he is not in this school. Now we have not any such complaints from girls (KII, school head teacher, Rupandehi).

According to qualitative data also exposed that schoolgirls are suffering from different types of mental health effects, where sexual harassment is a major cause behind sexual harassment but they also suffered from learning pressure as well.

\section{Perceived effects on mental health among adolescent girl students from different offenders}

The adolescent girl students were sexually harassed by the different offenders (teachers/school staff; male peers \&friends; \& neighbours and relatives). Due to such harassment, different types of mental illness and problems in students' academic and social performance were reported at different levels.

Table 2: Different types of mental health effects with the level of girl students due to sexual harassment by teacher/school staff

\begin{tabular}{llll}
\hline Response & Fear & Depressed & Irritation \\
\hline Never & $19 \%(69)$ & $14 \%(52)$ & $33 \%(116)$ \\
Sometime & $44 \%(162)$ & $34 \%(128)$ & $37 \%(132)$ \\
Often to very often & $37 \%(138)$ & $52 \%(192)$ & $30 \%(108)$ \\
\hline Total & $(369)$ & $(372)$ & $(356)$ \\
\hline
\end{tabular}

$\chi^{2=} 57.4 * * *, \mathrm{P}=0$

Note: Multiple responses case 372; Value in the parenthesis represents the number of respondents.

In the study majority of the respondents shared that they mainly felt fear and depression than irritation due to the sexual harassment from teachers. According to the data, $81 \%, 86 \%$, and $77 \%$ of the adolescent girl students were feeling depression, fear, and irritation respectively due to the sexual harassment of them by the teachers'/ school staff (Table 2) and 
the relationship between the types of mental health effects and its level (frequency) on the respondents were significantly dependent at $0.001 \%$ level $\left(\chi^{2}=57.4, \mathrm{P}<0.001\right)$.

During the focus group discussion, participants reported that fear, depression, irritation, frustration, tension, humiliation, and sleeping disorder were the common mental problems that they felt due to sexual harassment by the teacher on the frequency of "sometimes to frequently". Among different types of mental health effects, fear was the most common type due to the sexual harassment by the teachers. Following are a few opinions from the participants about their feeling and experiences due to sexual harassment by their teachers are as below:

I feel fear when I see a harassing teacher in the classroom and I cannot ask any questions and communicate with him because of his behaviours (FGD 1, Rupandehi, Community, R.N.5, Disadvantaged Janajati).

When I encounter the teacher who harasses us sexually, that time my body starts to vibrate and I could not stand properly because my legs become imbalanced, and weak. At that time, I assume that he would again harass me sexually at this time too. (FGD 5, Lalitpur, Community, R.N.5, Dalit).

My legs were trembling and sweating started from my body when I saw that bad teacher and it used to make me fear for many days and I used to be mentally weak. Even today, I feel fear when I remember that painful event. (IDI -G, Lalitpur, institutional, Janjati).

In the previous school, she was feeling fear, afraid and she did not have the interest to go to that school due to the sexual harassment by the teacher. Due to that reason, we changed her school and nowadays in the new school she is feeling better (KII, Parents of IDI- G, Lalitpur).

These results from quantitative and qualitative data illustrated that sexual harassment by teachers is a big factor responsible to create mental problems like fear, depression, and irritation in girl students. Similarly, adolescent girls have been feeling such types of bad emotion frequently. Statistically, different levels of mental health effects on girl students due to sexual harassment by the teachers were found significantly different according to the types of effects. 
Perceived mental health effect on the student due to the sexual harassment by peers and friends

The level of negative effects on the mental health of adolescent girl students that they supposed to happen to them due to the sexual harassment from peers and friends, were also analyzed. In course of analysis, it was found that the occurrence of the depressed, fear, and irritation were major perceived mental health problems that the respondents feel due to the sexual harassment of them by their male peer and friends and it was $87 \%, 89 \%$, and $75 \%$ respectively (Table 3 ).

Table 3: Different types and level of perceived mental health effects on girl students due to sexual harassment by peers/friends

\begin{tabular}{llll}
\hline $\begin{array}{l}\text { Level of mental } \\
\text { health effect }\end{array}$ & Feeling fear & $\begin{array}{c}\text { Feeling } \\
\text { Depressed }\end{array}$ & $\begin{array}{c}\text { Feeling } \\
\text { Irritation }\end{array}$ \\
\cline { 2 - 4 } Never & $13 \%(67)$ & $11 \%(57)$ & $25 \%(129)$ \\
Sometimes & $43 \%(224)$ & $43 \%(221)$ & $34 \%(173)$ \\
Often to very often & $44 \%(227)$ & $46 \%(242)$ & $41 \%(212)$ \\
\hline Total & $(518)$ & $(520)$ & $(514)$ \\
\hline
\end{tabular}

$\chi^{2=} 46.1 * * *, \mathrm{P}=0$

Note: Multiple responses case 520; Value in the parenthesis represents the number of respondents.

The relationship between the types of mental health effects and its level (frequency) on the respondents due to the sexual harassment by peers/ friends was found significantly dependent at $0.001 \%$ level $\left(\chi^{2}=46.1\right.$, $\mathrm{P}<0.001)$.

In course of qualitative data collection, participants reported that they felt depressed, irritated, frustrated, and tense, and humiliated because of peer's sexual harassment. During the focus group discussion, 72 participants who were sexually harassed said that they felt depressed and humiliated because of peer's sexual harassment. Some experiences of the girls which were expressed in focus group discussion were as follows:

One of my male friends used to harass and that used to make me depressed and sad. We feel humiliation when boys start harassing us. It makes us upset and makes us cry (FGD 5, Lalitpur, Community, R.N. 2, Janajati). 
I feel bored, depressed, and want to cry alone when I remember those misbehaviours and sexual harassment of boys to me on the way to and fro school (FGD 7, Lalitpur, Institutional, R.N. 1 Dalit).

I feel humiliated and angry and scold to god that he punishes us by making us women. It makes me cry and I weep lonely (FGD 10, Rupandehi, Community, R.N.6, Madeshi).

Analysis from the quantitative data and the verbatim of the adolescent girl students, it was found that the sexual harassment by peers and friends was responsible for creating depression, irritation, and fear on the girl students that is ultimately the crating poor mental health on the respondents.

\section{Perceived mental health effect on the student due to the sexual harassment by neighbors/relatives}

The girl students also had different types of mental health effects due to sexual harassment by neighbours and relatives at different levels (frequency). In course of the data analysis, the effects on social activities, creative activities, feeling fear, and depression were $76 \%, 70 \%, 84 \%$, and $85 \%$ of total respondents on a "Sometimes to Very often" basis respectively due to the sexual harassment by relatives and neighbour (Table 4).

Table 4: Different types and level of mental health effects on girl students due to sexual harassment by neighbour and relatives

\begin{tabular}{|c|c|c|c|c|}
\hline \multirow[b]{2}{*}{$\begin{array}{l}\text { Level of mental } \\
\text { health effect }\end{array}$} & \multicolumn{4}{|c|}{ Types of mental health effects } \\
\hline & $\begin{array}{c}\text { Social } \\
\text { activities }\end{array}$ & $\begin{array}{l}\text { Creative } \\
\text { activities }\end{array}$ & $\begin{array}{c}\text { Feeling } \\
\text { fear }\end{array}$ & Depressed \\
\hline Never & $24 \%$ (139) & $30 \%(175)$ & $16 \% \quad($ & $15 \%(89)$ \\
\hline Sometime & $45 \%(263)$ & $41 \%(237)$ & & $\begin{array}{lrl}4 & 3 & \%\end{array}$ \\
\hline $\begin{array}{l}\text { Often to very } \\
\text { often }\end{array}$ & $31 \%(183)$ & $29 \%(165)$ & & $\begin{array}{l}420 \\
(241)\end{array}$ \\
\hline Total & $(585)$ & (577) & $(580)$ & (580) \\
\hline
\end{tabular}

$\chi^{2}=60.75^{* * *}, \mathrm{P}=0$

Note: Multiple response cases 580; Value in parenthesis represents the number of respondents.

During the chi-square test, the relationship between the types of mental health effects and its level (frequency) on the respondents due to the 
sexual harassment by neighbour and relatives was significantly dependent at $0.001 \%$ level $\left(\chi^{2}=60.75, \mathrm{P}=0.001\right)$.

In focus group discussion and in-depth interview (IDI) during the qualitative study, the participants shared that they felt fear, humiliation, and depression due to the sexual harassment by relatives and neighbours. Following are the representative verbatim of the adolescent girl students about their perception due to the sexual harassment by their relatives and neighbour.

My uncle used to sexually harass me at my home. After some time, I shared my problem with my mom but she said that he had done much helps for us so she asked me to be silent and try to be safe by myself. I could not cope with the situation normally and I was depressed and was feeling fear with his (IDI -H, Lalitpur, Community, Janjati).

Once, my sister-in-law tried to sexually assault and rape me in a hotel in a nearby town. It made me very depressed, feared, and insecure. After that incident, it became hard for me to sleep properly and concentrate on my study, and now I am trying to forget that black history and trying to make me strong. Still, it is very difficult to recover (IDI-D, Rupandehi, Institutional, Dalit).

There is a mature man in our area and when we walk along the way he makes a whistle and gaze in our body and mostly, he drinks alcohol too. Due to his behaviour, we feel fear to walk along the street. (FGD 8, Lalitpur, Community, R.N. 6, Janjati).

My daughter complained me about the sexual harassment which she got from my husband's brother. Because of his bad behaviour; she was feeling depressed, nervous, and frightened. As it was from my family member, I could not say anything to the perpetrators and I was compelled to keep such crime within two-person that was me and my daughter. I am also feeling bad in this context (KII, Parent of the victim, Lalitpur,).

The analyses of quantitative and qualitative data also showed that sexual harassment by neighbours and relatives was responsible for creating mental health effects on girl students.

From all the above-mentioned results from the quantitative and qualitative data analysis, the prevalence of depression, anxiety, and stress was found among the adolescent girl's students. The DASS test showed that $45 \%$ of the girl students who were sexually harassed by different persons, 
were suffering from depression, $35 \%$ of the students were suffering from different levels of stress and $52 \%$ of the girl students had different level of anxiety. The depression anxiety and stress level were predominant in the adolescent girl students from both community and institutional schools as well as in Lalitpur and Rupandehi districts too. Among the different levels of depression, stress, and anxiety, a mild to moderate level of negative effects were prevalent whereas cases of the extreme level of depression, stress, and anxiety were relatively lower (less than 5\%).

Not only in this study but sexual harassment was pointed out as one of the causes behind negative effects on victim's mental health effect on different national and international studies (Richman et al. 1999, Rospenda et al. 2009). Sexual harassment was also found as a factor of negative mental health in the form of depression, anxiety, and stress in nurses of public hospitals too (Mushtaq, Sultana and Imtiaz 2015). Some researchers (Bagley et al. 1997, Jones et al. 2008, MSI 2008, Rowe 1996) also illustrated the negative consequences of sexual harassment to students such as children's health and safety, enrolment, and learning achievement dignity, and self-esteem. Fredrickson and Roberts (1997) mentioned that the outcomes of chronic stress which is also one of the reported outcomes of harassment called chronic unexpected stress (CUS) which increased inflammation in several brain areas on the victim. Hence, sexual harassment is not only seen as a social crime but also has very severe effects on human physical and mental health that was found responsible to increase the stress, anxiety, depression to reduce the confidence, creativity internal capacity of the victim. The effect of sexual harassment was found higher in the case of anxiety in our context too. In a focus group, discussion and in-depth interview participants shared that they felt fear, irritation, and depression because of sexual harassment that happened by their peers/friends, teachers, and relatives.

Along with the depression, anxiety, and stress, different other types of mental problem such as fear, irritation, frustration, tension, humiliation, and sleeping problem (insomnia) were mentioned by the participants during qualitative inquiry due to sexual harassment by teachers, peers/friend and relatives/neighbour. These types of mental illness due to sexual harassment were reported in many international studies too. MIS (2008) reported that $68 \%$ of the girl students felt very or somewhat upset by sexual harassment along with $57 \%$ of the girl students reported feeling self-conscious or embarrassed and $55 \%$ of the girl students reported feeling angry. Anderson 
(2011) and Hill and Kearl (2011) also reported poor emotional effects on girl students due to sexual harassment and reported that nearly half of the girls in the USA and $87 \%$ of the girls who were also having negative mental effects, such as absenteeism, poor sleep, and stomach-ache. In the Nepalese context, the rate of prevalence of sexual harassment and its negative effect on the mental health of adolescent girl students has similar effects but the minor differences might be due to our cultural ethics, social systems, and traditional values where the girls usually hesitated to express their problems due to fear of victim-blaming in society. In Nepalese culture, it is common to keep secret the sexual harassment cases by the victim within herself forcefully might be due to fear of victim blaming and poor hope of justice. Such suppression of torture and pains of sexual harassment might the causes behind the mental ill-health on the adolescent girl students in Nepal.

\section{CONCLUSIONS}

Mental illness status was found among the adolescent girl students who were suffered from sexually harassed and it was also found as one of the responsible factor in reducing mental health status that is depression, anxiety and stress on the victim. Similarly, girls were also feeling fear, frustration, irritation, and insomnia in their daily life due to the sexual harassment by teachers, male class friends, and relatives. Such misbehaviours against on them might affect their physical health and educational performance along with their poor mental health status. As school is considered as the temple of learning and students come there to learn required knowledge and skill to be a capable and good citizen in future. Hence, for a better learning environment, there should smooth and harassment free learning environment so that students can explore their capacity to be efficient citizens of the nation.

\section{REFERENCES}

AAUW. (2001). Hostile hallways: Bullying, teasing, and sexual harassment in school. Washington: American Association of University Women.

Afzali,A., Delavar,A., Borjali,A. \& Mirzamani, S.M., (2007). Psychometric properties of DASS-42 as Accessed in a sample of Kermanshah high school students. Journal of Research in Behavioural Sciences, 5: 81-92.

Anderson, J. (2011). A national study finds widespread sexual harassment of students in grades 7 to 12, http://www.nytimes.com/2011/11/07 
education/widespread-sexual-harassment-in-grades-7-to-12found-in-study.html? _r=0.

Bagley, C., Bolitho, F., \& Bertrand, L. (1997). Sexual assault in school, mental health and suicidal behaviors in adolescent women in Canada. Adolescence, 32: 361-366.

Basha, E. \& Kaya, M. (2016). Depression, anxiety and stress scale (DASS): The study of validity and reliability. Universal Journal of Educational Research, 4(12): 2701-2705. https://doi.org/10.13189/ ujer.2016.041202.

Berman, H., McKenna, K., Arnold, C. T., Taylor, G., \& MacQuarrie, B. (2000). Sexual harassment: Everyday violence in the lives of girls and women. Advances in Nursing Science, 22(4): 32-46.

Creswell, J.W. (2014). Research design qualitative, quantitative and, mixed method approaches. Sage publication Inc. 4th Ed.

Crick, N. R., \&Bigbee, M. A. (1998). Relational and overt forms of peer victimization: A multi in formant approach. Journal of Consulting and Clinical Psychology, 66(2): 337-347. http://doi. org/10.1037/0022-006X.66.2.337.

Dahinten, S. V. (1999). Peer sexual harassment: A barrier to the health of adolescent females? Canadian Journal of Nursing Research, 31(2): 41-52.

Farley, L. (1978.) Sexual shakedown: The sexual harassment of women on the job. New York: McGraw-Hill.

Fredrickson B.L. \& Roberts, T.A (1997) Objectification theory, toward understanding women's lived experiences and mental health risks. Psychology of Women Quarterly, 21(2): 173-206, https://doi.org/ 10.1111/j.1471- 6402.1997.tb00108.x.

Gyawali, K., Neupane, I., Aryal, N. \& Thapa, A. (2012). Sexual harassment and its impact on education among teenage girls student in Kathmandu metropolitan city. University Grant commission, Nepal.

Hill, C., \& Kearl, H. (2011). Crossing the line: Sexual harassment at school. American Association of University Women. Washington DC.

Jones, N, Karen Moore, K., Eliana Villar-Marquez, E.V., \& Broadbent, E. (2008). Painful lessons: The politics of preventing sexual violence and bullying at school. Overseas Development Institute Working 
Paper 295 Results of ODI research presented in preliminary form for discussion and critical comment, London.

Lee, V. E., Croninger, R. G., Linn, E., \& Chen, X. (1996). The culture of sexual harassment in secondary schools. American Educational Research Journal, 33(2): 383-417.

Lovibond, S.H. \& Lovibond, P.F. (1995). Manual for the depression anxiety stress scales. (2 ${ }^{\text {nd }}$. Ed.). Sydney: Psychology Foundation.

Mishra, D., \& Lamichhane, J. (2018). Experience of sexual harassment in public transport among female health science students: A cross sectional study of Kathmandu, Nepal. Journal of Manmohan Memorial Institute of Health Sciences, 4(1): 20-32.

Nieuwenhuijsen K., Boer A.G.E.M., \& Verbeek J.H.A.M,(2003).The Depression anxiety stress scales (DASS): Detecting anxiety disorder and depression in employees absent from work because of mental health problems. Occupational and Environmental Medicine 60:77-82.

Mohapatra, H. (2015). Status of women in Indian society. Journal of Research in Humanities and Social Science, 3(6): 33-36. http:// www.questjournals.org/ jrhss/papers/vol3-issue6/F363336.pdf.

MSI. (2008). Are schools safe haven for children? Examining school related gender based violence. Washington D.C, US agencies for international development. http://www.usaid.gov/our_work/ crosscutting_programs/wid/pubs/Safe_Havens _ final. Pdf.

Mushtaq, M., Sultana, S. \& Imtiaz, I. (2015). The trauma of sexual harassment and its mental health consequences among nurses. Journal of the College of Physicians and Surgeons-Pakistan: JCPSP, 25(9): 675-679.

Okeke, S.,\& Carina M. A. (2011). Impact of sexual harassment on women undergraduates' educational experience in Anambra State of Nigeria (2011). Dissertations. Paper 6. http://scholarship.shu.edu/ dissertations/6.

Plan. (2008). Learn without fear: The global campaign to end violence in schools. Woking: Plan.

Richman, J. A. (2011). Sexual harassment and generalized workplace abuse among university employees: prevalence and mental health correlates. American Journal of Public Health, 89: 358-363, https:// doi.org/10.2105/ AJPH.89.3. 358. 
Rospenda, K., Richman, J., \& Nawyn, S. (1998). Doing power. The confluence of gender, race, and class in contra power sexual harassment. Gender \& Society, 12(1): 40-60.

Rowe, M. P. (1996). Dealing with harassment: A systems approach. In: M. S. Stockdale (ed.), Sexual harassment in the workplace: Perspectives, frontiers, and response strategies. Thousand Oaks, CA: Sage. pp. 241-271.

Rowe, M.P. (1973) Saturn's ring. In graduate and professional education of women, Washington, DC.

Thapalia, R., Dhungana, R., Adhikari, S., \& Pandey, A. (2020). Understanding, experience and response to sexual harassment among the female students: A mixed method study. Journal of Nepal Health Research Council, 17(4): 424-430.

Tran T.D., Tran, T., \&Fisher,J.(2013). Validation of the depression anxiety stress scales (DASS) 21 as a screening instrument for depression and anxiety in a rural community-based cohort of northern Vietnamese women. BMC Psychiatry. 13(24). https://doi.org/10.1186/1471244X-13-24.

UN Women. (2009). Convention on the elimination of all forms of discrimination against women. https://www.un.org/womenwatch/ daw/cedaw/recommendations/ recomm. htm\#recom19

USMPB. (1985). Sexual harassment in the federal workplace: Trends, progress, continuing challenges. Washington, DC: U. Government Printing Office.

World Health Organization (2004). Promoting mental health: concepts, emerging evidence; practice (Summary Report). Geneva: World Health Organization. 